\title{
Myofibroblast proliferation, fibrosis, and defective pancreatic repair induced by cyclosporin in rats
}

\author{
E Vaquero, X Molero, X Tian, A Salas, J-R Malagelada
}

\begin{abstract}
Background-Full recovery is always achieved after caerulein induced pancreatitis. Cyclosporin stimulates transforming growth factor $\beta$ (TGF- $\beta$ ) and may interfere with pancreatic regeneration.

Aim-To investigate the effects of cyclosporin after caerulein induced pancreatitis or after caerulein injury.

Methods-Protocol A: rats received cyclosporin daily $(20 \mathrm{mg} / \mathrm{kg})$ and caerulein pancreatitis was induced on days 2 and 8 . Protocol B: six courses of caerulein pancreatitis were induced at weekly intervals. Cyclosporin was administered on induction and the day before. Rats recovered for two weeks before being killed. Control groups received saline, cyclosporin, or caerulein alone.
\end{abstract}

Results-Protocol A: plasma TGF- $\beta 1$ and tissue collagenase rose after pancreatitis but decreased towards baseline values on day 15 , matching a low collagen content. Morphology disclosed minimal inflammatory infiltration and some interstitial cells immunoreactive for smooth muscle $\alpha$-actin (SMA). TGF- $\beta 1$ increased, and remained high in cyclosporin treated groups (cyclosporin alone and cyclosporin plus caerulein). Rats treated with cyclosporin and caerulein showed severe pancreatic weight reduction, abundant inflammatory infiltrates, increased SMA immunoreactive interstitial cells, high collagen content, and delayed collagenase response. No SMA immunoreactive cells were detected in normal rats. Cyclosporin alone also increased SMA immunoreactive cells, despite the absence of inflammatory infiltration and fairly conserved pancreatic structure. Protocol B: the combined pulse treatment induced appreciable collagen deposition and resulted in a smaller pancreas than controls. Morphological examination showed atrophy, fibrosis, fibroblast proliferation, and mononuclear infiltrates.

Conclusion-Cyclosporin greatly distorts pancreatic repair, transforming caerulein induced pancreatitis into a fibrotic chronic-like disease. The mechanism involves TGF- $\beta$, myofibroblasts, and defective collagenase activation. (Gut 1999;45:269-277)

Keywords: chronic pancreatitis; transforming growth factor $\beta$; caerulein; cyclosporin; fibrosis; myofibroblast
Caerulein hyperstimulation induces acute oedematous pancreatitis in rats. Despite morphological and biochemical evidence of pancreatic injury, complete recovery is the rule. Restoration of normal pancreatic architecture and function after caerulein induced pancreatitis involves controlled and transient increases in transforming growth factor factor $\beta$ (TGF$\beta)$, fibroblast proliferation, collagen formation, and activation of tissue proteinases. The reparative process is so highly coordinated that scarring, signs of atrophy, inflammatory cells, or distortion of pancreatic morphology cannot be recognised a few days after the caerulein challenge. ${ }^{1-6}$

Moreover, even repeated bouts of caerulein induced pancreatitis fail to cause permanent damage to the pancreas, ${ }^{7}$ indicating that either the injury is not severe enough to overcome a number of non-specific tissue defences or that highly efficient regenerative mechanisms are activated. Nonetheless, experimental manipulations, such as infusion of TGF- $\beta^{8}$ or stress ${ }^{9}$, may disrupt the reparative sequence and result in defective regeneration.

Cyclosporin is widely used in clinical practice, particularly to prevent rejection of organ transplantation. It binds to cyclophilin and inhibits calcineurin, a serine-threonine phosphatase. ${ }^{10}$ This property may account for its wide biological actions such as immunosuppression, vasoconstriction, ${ }^{11}$ and stimulation of TGF- $\beta$ expression. ${ }^{12-14}$ Although cyclosporin accumulates in high concentrations in the pancreas, ${ }^{11-15}$ it only produces minor morphological or functional derangements. ${ }^{16}{ }^{17}$ Even after several days of a large dose regimen, cyclosporin does not induce an acute inflammatory reaction over the pancreas. ${ }^{17}$

In the kidneys, heart, and gums, cyclosporin is known to promote collagen deposition. ${ }^{18-20}$ In the present study we tested the hypothesis that, in the pancreas, cyclosporin exerts its fibrogenic potential by interfering with the highly efficient reparative processes that are activated after caerulein hyperstimulation, resulting in poor gland regeneration and enhanced collagen deposition.

Materials and methods

MATERIALS

Caerulein, hydroxyproline, azocoll, calf thymus DNA standards, Hoechst compound 33258 (bisBenzimide) and anti-smooth muscle $\alpha$-actin (SMA) monoclonal antibody were from Sigma. BCA reagent and bovine serum

Abbreviations used in this paper: SMA, smooth muscle $\alpha$-actin; TGF, transforming growth factor.

119-129, 08035 Barcelona, 

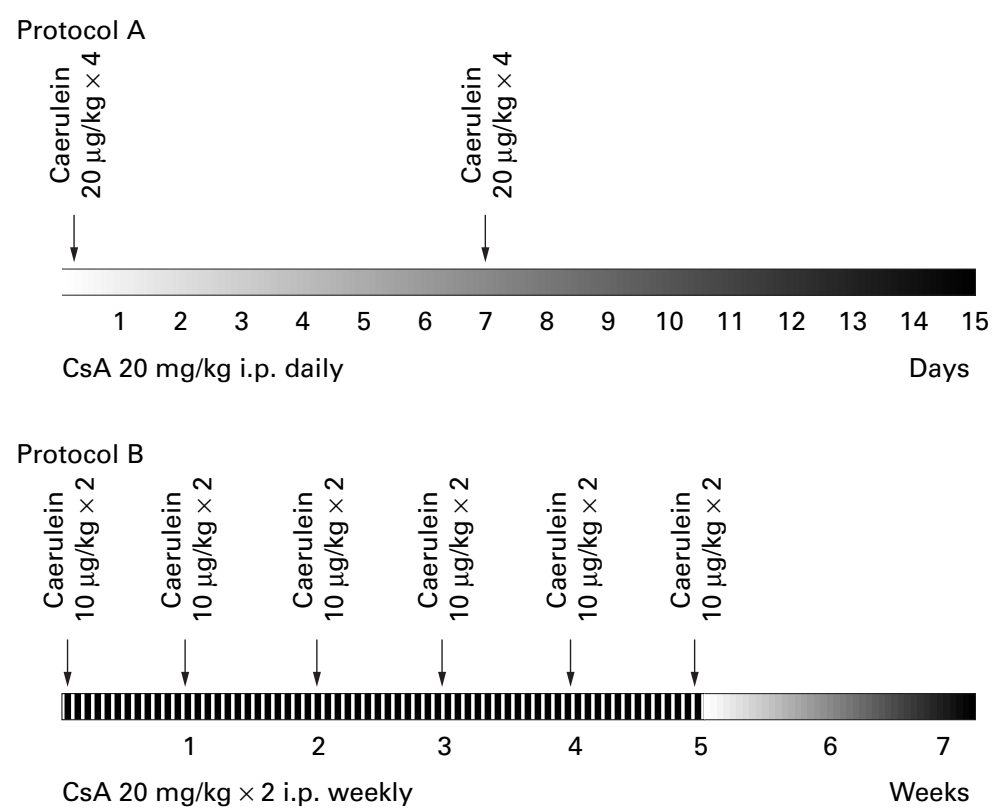

Figure 1 Schematic representation of the experimental schedule for protocols $A$ (in days) and $B$ (in weeks). Solid arrows denote bouts of caerulein induced acute pancreatitis. Cs $A$, cyclosporin; i.p., intraperitoneal.

albumin standard for protein determination were from Pierce (Rockford, Illinois, USA). Labelled streptavidin-biotin (LSAB) kit was from Dako Corporation (Carpinteria, CA, USA). Cyclosporin was from Sandoz Pharma SAE (Barcelona, Spain).

TGF- $\beta 1$ test kit was from Genzyme (Cambridge, Massachusetts, USA).

METHODS

All experiments were performed on $300 \mathrm{~g}$ male Wistar rats housed in rack mounted cages under conditions of constant temperature and a 12 hour lighting cycle.

\section{Experimental procedures}

To examine the effects of cyclosporin on pancreatic regeneration after acute oedematous pancreatitis, two main protocols were followed (fig 1). In protocol A we evaluated the early cyclosporin induced events after acute oedematous pancreatitis (fig 1). Intraperitoneal daily doses of cyclosporin $(20 \mathrm{mg} / \mathrm{kg}$ diluted $1: 4$ in saline) were administered for 15 days. On days 1 and 8 , acute pancreatitis was induced by four intraperitoneal injections of caerulein $(20 \mu \mathrm{g} / \mathrm{kg})$ one hour apart $(\mathrm{CR}+\mathrm{CsA}$ group). Three other groups followed the same experimental procedure except that they received caerulein (CR group), cyclosporin (CsA group) or vehicle (control group) alone. In each experimental condition, groups of 12 rats were killed on days 3, 7, 11 and 15 and pancreata were excised for histopathological examination $(n=6)$ or for biochemical assays $(n=6)$. Before the animals were killed, blood was withdrawn by cardiac puncture using heparinised syringes, and plasma was obtained for TGF- $\beta 1$ determination.

In protocol $\mathrm{B}$ we evaluated cyclosporin induced long term accumulation of fibrotic tissue under milder conditions (fig 1). At weekly intervals, six episodes of acute pancreatitis were induced in rats by intraperitoneal administration of only two doses of caerulein $(10 \mu \mathrm{g} / \mathrm{kg})$ one hour apart. Cyclosporin $(20 \mathrm{mg} / \mathrm{kg})$ was given intraperitoneally the day before and the same day that pancreatitis was induced. For the next five days (until the next pancreatitis induction) rats received no further treatment. After the last induction, rats were allowed to recover for two weeks except for a single weekly dose of cyclosporin. Pancreata were then excised, weighed, and processed either for light microscopy or for biochemical assays (CR+CsA group). Three other groups of rats followed the same treatment protocol except that they received vehicle, cyclosporin, or caerulein alone ( $\mathrm{n}=12$ per group).

\section{Morphology}

Pancreatic specimens were fixed in $10 \%$ formalin and embedded in paraffin wax. Several sections were cut and stained with haematoxylin-eosin or Masson trichrome stain. When indicated, immunohistochemistry was performed with the monoclonal anti-SMA antibody ( $\alpha$-SMA) to identify myofibroblasts (interstitial $\alpha$-SMA positive cells with fibroblast-like shape) using the avidin-biotinperoxidase complex system (LSAB kit, Dako Corporation). Quantitative analysis of interstitial $\alpha$-SMA positive cells was performed at 400 $\times$ final magnification. Ten non-overlapping fields were evaluated for each animal in each treatment group.

Histological slides were examined by the participating pathologist (AS) who was unaware of the tissue source.

\section{Biochemical determinations}

For biochemical assays, total pancreata were excised, trimmed of fat and lymph nodes, weighed, frozen, and lyophilised. A powder was made in a mortar from the dried residue and resuspended in ice cold distilled water (100 $\mathrm{mg} / \mathrm{ml}$ ). Pancreatic homogenates were prepared by serial use of a motor driven shearer (Tissue Tearor 985-370; Biospec Products Inc, Drewel, Wisconsin, USA) and Dounce tissue homogenisers on ice.

Total protein and hydroxyproline content were quantified from crude homogenates. Protein concentration was determined by BCA reagent.

Hydroxyproline content was determined as described $^{2122}$ with minor modifications. Briefly, an aliquot of $200 \mu \mathrm{l}$ of crude homogenate was placed in a $10 \mathrm{ml}$ ampoule containing $2 \mathrm{ml} 6 \mathrm{M}$ $\mathrm{HCl}$ and sealed. Hydrolysis was performed at $110^{\circ} \mathrm{C}$ for 16 hours. The hydrolysate was dried, and the sediment redissolved in $2 \mathrm{ml}$ distilled water and dried again. The latter step was repeated three times before the residue was resuspended in $3 \mathrm{ml} 0.2 \mathrm{M}$ citrate buffer $(\mathrm{pH}$ 2.2). A $1 \mathrm{ml}$ portion of the sample or $1 \mathrm{ml}$ of hydroxyproline standards (to establish the calibration curve) was placed in a Pyrex test tube and mixed with $1 \mathrm{ml}$ chloramine $\mathrm{T}$ solution prepared as described by Rojkind and Gonzalez. ${ }^{21}$ After a 20 minute incubation period, the reaction was stopped by the sequential addition of $0.5 \mathrm{ml}$ sodium thiosul- 
phate (2 M), $1 \mathrm{ml} \mathrm{NaOH}(1 \mathrm{M})$, and $2 \mathrm{~g} \mathrm{NaCl}$. Proline was extracted in $2.5 \mathrm{ml}$ toluene by shaking the contents for 30 seconds. The aqueous fraction was placed in a boiling water bath for 30 minutes and cooled to room temperature. Hydroxyproline was extracted in $2.5 \mathrm{ml}$ toluene and determined by the use of Ehrlich's reagent.

In these experiments we measured total biologically active collagenases in crude homogenates by a method that uses a collagen bound dye (azocoll) as substrate ${ }^{23}$ with minor modifications. Briefly, $0.25 \mathrm{~g}$ of the insoluble collagen-dye conjugate azocoll was suspended in $50 \mathrm{ml} 50 \mathrm{mM}$ Tris/ $\mathrm{HCl} / 1 \mathrm{mM} \mathrm{CaCl}{ }_{2}(\mathrm{pH}$ 7.8) and stirred for 10 minutes. Azocoll was then allowed to sediment, the supernatant discharged, and the sediment resuspended in the same buffer containing aprotinin $(140 \mu \mathrm{g} / \mathrm{ml})$ to prevent azocoll hydrolysis by other pancreatic proteases. ${ }^{24}$

Crude homogenates were sonicated before DNA measurement. Total DNA was assayed as described $^{25}$ by incubating $20 \mu$ l of sonicated tissue homogenates with Hoechst compound $33258(1 \mu \mathrm{g} / \mathrm{ml}$ final concentration) in phosphate/saline buffer $\left(0.05 \mathrm{M} \mathrm{NaPO}_{4}, 2 \mathrm{M}\right.$ $\mathrm{NaCl}, \mathrm{pH} 7.4$ ) for 30 minutes. Fluorescence measurements were made using an SFM 25 fluorimeter (Tegimenta AG, Rotkreuz, Switzerland), setting the excitation light to $356 \mathrm{~nm}$ and the emission light to $458 \mathrm{~nm}$. The DNA concentration of each sample was calculated from extrapolation on a standard curve constructed with calf thymus DNA.

To measure biologically active TGF- $\beta 1$ concentration in plasma, samples and standards were acidified using $\mathrm{HCl}$ for one hour and then neutralised to $\mathrm{pH} 7.0-7.4$ before the enzyme linked immunosorbent assay.

Assessment of pancreatitis severity

To elucidate whether or not cyclosporin worsened the oedematous acute pancreatitis induced by caerulein, we measured amylasaemia, tissue oedema, and myeloperoxidase activity six hours after inducing acute pancreatitis. A specimen from the head of the pancreas was also processed for histological examination. Amylase activity was determined by the $\alpha$-amylase EPS test (Boehringer) for $\mathrm{BM} /$ Hitachi system 717 . Aliquots $(200 \mu \mathrm{l})$ of $1: 800$ dilutions of the sample were used in the assay.

To measure pancreatic oedema, excised pancreata were wet weighed, desiccated at $160^{\circ} \mathrm{C}$ for 24 hours, and reweighed. Pancreatic water content was calculated as percentage of total wet weight.

Tissue myeloperoxidase activity was used as a biochemical marker of polymorphonuclear infiltration. It was measured in pancreatic homogenates using a previously described method $^{26} 27$ that measures myeloperoxidase activity as the result of $\mathrm{H}_{2} \mathrm{O}_{2}$ dependent oxidation of 3,3',5,5'-tetramethylbenzidine and expressed as units per mg of protein.

Statistical analysis

Values are expressed as mean (SEM). Student's $t$ test was used when two variables were

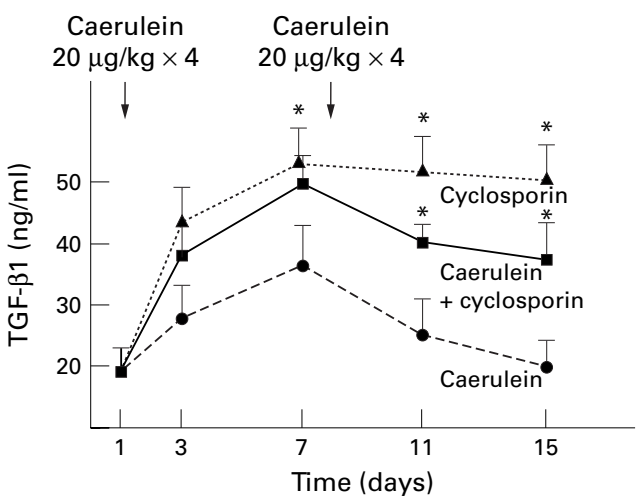

Figure 2 Time course of plasma transforming growth factor $\beta 1$ (TGF- $\beta 1$ ) concentration in response to caerulein induced acute pancreatitis and to daily cyclosporin treatment. Acute pancreatitis was associated with a moderately transient rise in plasma TGF- $\beta 1$. Cyclosporin, whether administered alone or in combination with bouts of pancreatitis, induced a larger and steadier increase throughout the full observation period. ${ }^{\star} p<0.05 v$ caerulein alone.

compared. When more than two variables were present, group means were compared by analysis of variance followed by Fisher's protected least significant differences test. Differences were regarded as significant at $p<0.05$.

\section{Results}

PROTOCOL A: EFFECTS OF DAILY CYCLOSPORIN TREATMENT ON THE EARLY PHASE OF PANCREATIC REGENERATION

Cyclosporin treatment did not aggravate caerulein induced pancreatitis, as assessed by serum amylase (45.7 (6.9) v 70.7 (13.7) $\mathrm{U} / \mathrm{ml}$; $\mathrm{p}=0.12)$, tissue oedema $(83.2(2.3) v 87.1$ $(0.7) \% ; \mathrm{p}=0.4)$, and myeloperoxidase activity (311 (54) v 344 (70) $\mathrm{mU} / \mathrm{mg}$ protein; $\mathrm{p}=0.8$ ). Furthermore, contrary to previous reports, ${ }^{28}$ no haemorrhages could be identified in pancreata from rats receiving the combined treatment of cyclosporin plus caerulein, by either macroscopic or microscopic inspection.

\section{Plasma TGF- $\beta$ concentration}

In close agreement with previous reports in humans and mice, ${ }^{13} 14$ plasma levels of TGF- $\beta$ in rats treated with cyclosporin were found to be well above control values of 19 (3) $\mathrm{ng} / \mathrm{ml}$, in both the CR+CsA and CsA groups (fig 2). TGF- $\beta$ also increased, but to a lesser extent, in the CR group but had returned to baseline values by the end of the observation period.

\section{Hydroxyproline concentration and collagenase} activity in pancreatic homogenates

Tissue hydroxyproline increased soon after pancreatitis in the CR group. This enhancement in collagen formation was matched by a reciprocal increase in pancreatic collagenase activity, and both remained slightly elevated in response to a second induction of pancreatitis (fig 3). In contrast, tissue collagenase in the CR+CsA group was low after pancreatitis, despite an elevated hydroxyproline content, but increased with time and became very high by the end of the observation period in the face of increased tissue hydroxyproline concentration (fig 3), which suggests defective extracellular matrix remodelling. 

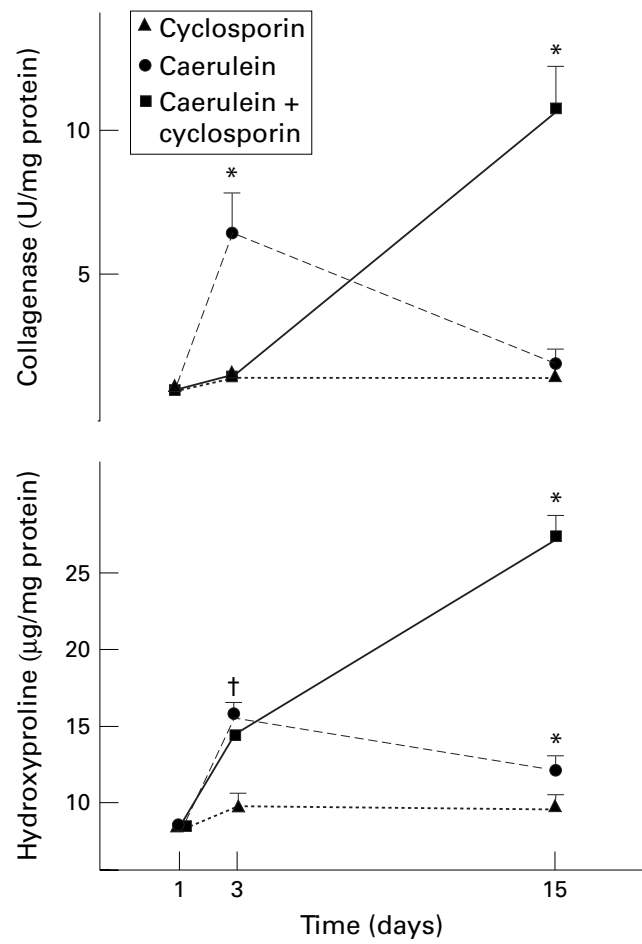

Figure 3 Tissue collagenase activity and hydroxyproline concentration at days 3 and 15 after initiation of the experiments in protocol A. Collagenase activity and hydroxyproline content increased soon after pancreatitis induction, but declined by the end of the observation period. In contrast, cyclosporin delayed the collagenase response and notably increased collagen deposition. ${ }^{\star} p<0.05 v$ all other groups in the same time period. $t p<0.05 v$ cyclosporin alone.

Pancreatic weight and total protein

Both variables are widely used to quantify pancreatic gland atrophy. Pancreatic weight and protein content decreased after each bout of pancreatitis in the caerulein alone group, but recovered thereafter (fig 4). In contrast, when rats also received cyclosporin, pancreatic weight and protein decreased further and did not recover. Cyclosporin alone had no measurable effects after 15 days of treatment on pancreatic weight or total protein content (3.2 $(0.1) \mathrm{g} / \mathrm{kg}$ body weight and $102(5.2) \mathrm{mg}$ ) as compared with saline (3.2 (0.2) and 97 (10); $\mathrm{p}>0.05$ for both variables).

\section{Morphological findings}

At the end of the observation period, neither cyclosporin nor caerulein alone had produced significant alterations in pancreatic structure. Loose connections between adjacent acini, a certain degree of fat atrophy, and some cells with cytoplasmic vacuolisation could be observed after cyclosporin, and, two weeks after the initial caerulein challenge, pancreatic morphology in the caerulein alone group was grossly restored, except for occasional inflammatory infiltrates (fig 5). In contrast, pancreatic specimens from the CR+CsA group showed diffuse infiltration with inflammatory mononuclear and polynuclear cells, surrounding areas of gland atrophy. There was also increased connective tissue and fine bands of collagen that were best visualised by Masson trichromic staining (data not shown).

Fibroblast-like cells immunoreactive for $\alpha$-SMA have contractile capabilities and are considered to be myofibroblasts. Immunostaining with anti- $\alpha$-SMA allowed quantification of myofibroblasts in pancreatic parenchyma (fig 6). Normal pancreatic tissue contained no interstitial cells exhibiting immunoreactivity for $\alpha$-SMA. At the end of the observation period in the caerulein alone group, myofibroblasts (interstitial $\alpha$-SMA immunoreactive cells) displayed an elongated

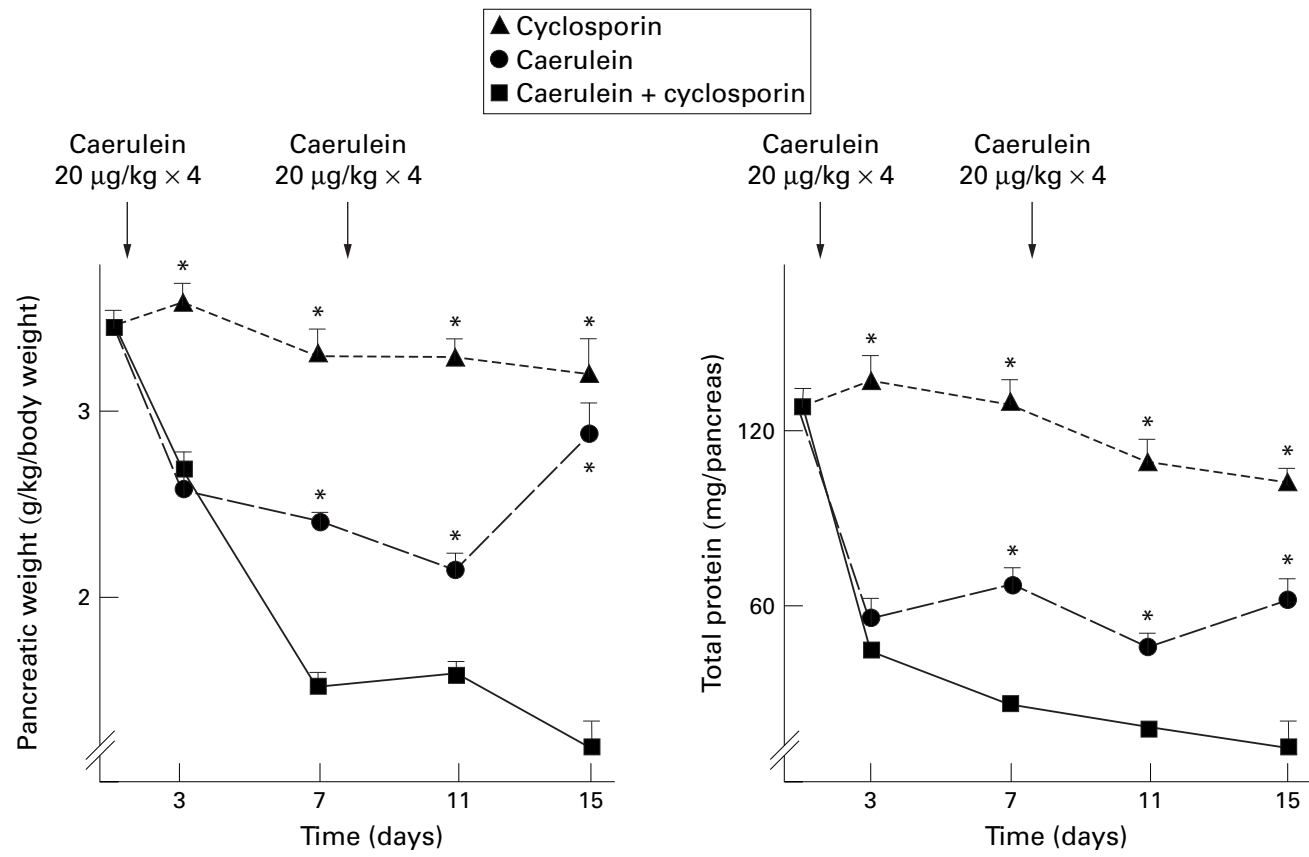

Figure 4 Effects of cyclosporin on recovery of pancreatic weight and protein content after caerulein induced pancreatitis (protocol A). Induction of caerulein pancreatitis substantially reduced pancreatic weight and protein content. Addition of cyclosporin resulted in a continuous fall in pancreatic weight and protein and precluded recovery as measured by these two markers of atrophy. ${ }^{*} p<0.05 v$ caerulein + cyclosporin. Arrows denote episodes of pancreatitis induction. 

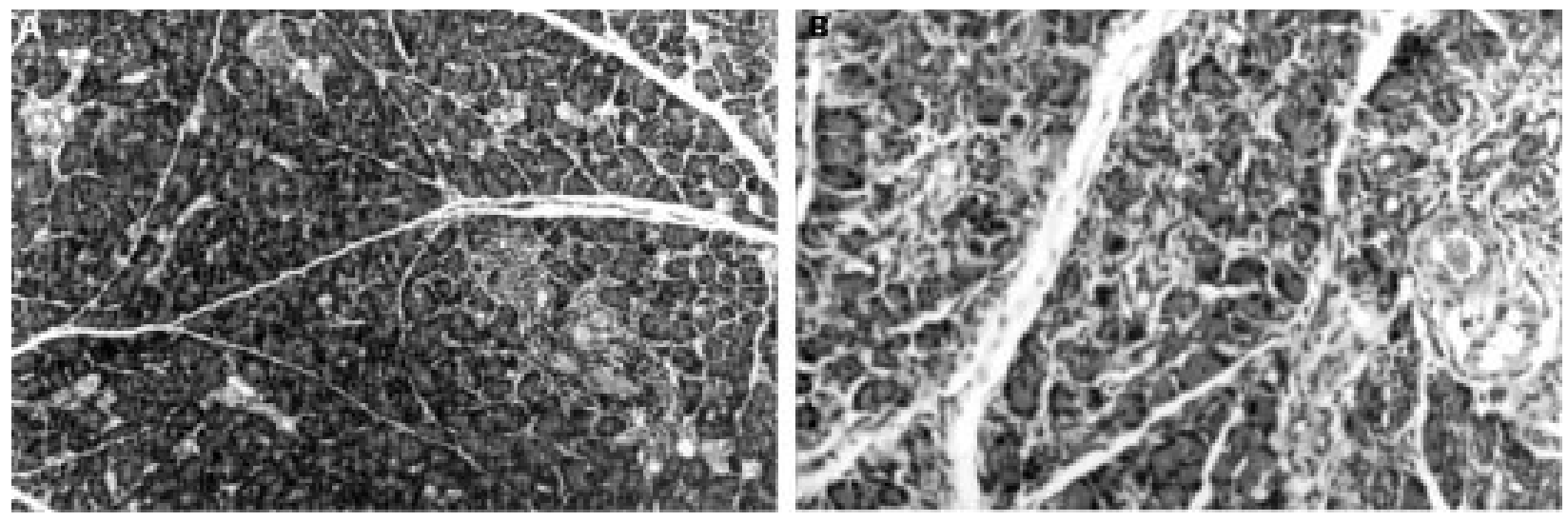

Figure 5 Histological features of the pancreas 15 days after initiation of protocol $A$ schedule (two pancreatitis inductions one week apart). (A) Caerulein alone group (haematoxylin and eosin stain; original magnification $\times 200$ ). (B) Caerulein + cyclosporin group (haematoxylin and eosin stain; original magnification $\times 250$ ). Pancreas from the caerulein alone group had a normal appearing parenchyma with occasional discrete mononuclear infiltrates. Specimens from the caerulein + cyclosporin group showed evident signs of persistent tissue damage such as increased connective tissue deposition associated with diffuse lymphomononuclear infiltrates and areas of gland atrophy.

shape and could be observed scattered among well structured acini throughout the parenchyma of the pancreas (fig $6 \mathrm{~B}$ ). In the CR+CsA group, myofibroblasts were significantly increased in number compared with the $\mathrm{CR}$ group (figs $6 \mathrm{D}$ and 7 ). They were mainly distributed in association with areas of excess connective tissue accumulation and inflammatory cell infiltrates. Interestingly, in the pancreas of rats receiving cyclosporin alone, myofibroblasts were also a prominent feature on morphological inspection (figs 6C and 7). They were increased in number as compared with controls and were found evenly distributed in parenchyma with minimal structural disturbances and no inflammatory infiltrates.

PROTOCOL B: EFFECTS OF WEEKLY PULSES OF CYCLOSPORIN ON LONG TERM PANCREATIC RECOVERY AFTER REPEATED BOUTS OF CAERULEIN INDUCED PANCREATITIS

The main aim of this protocol was to assess the persistence of pancreatic collagen deposition
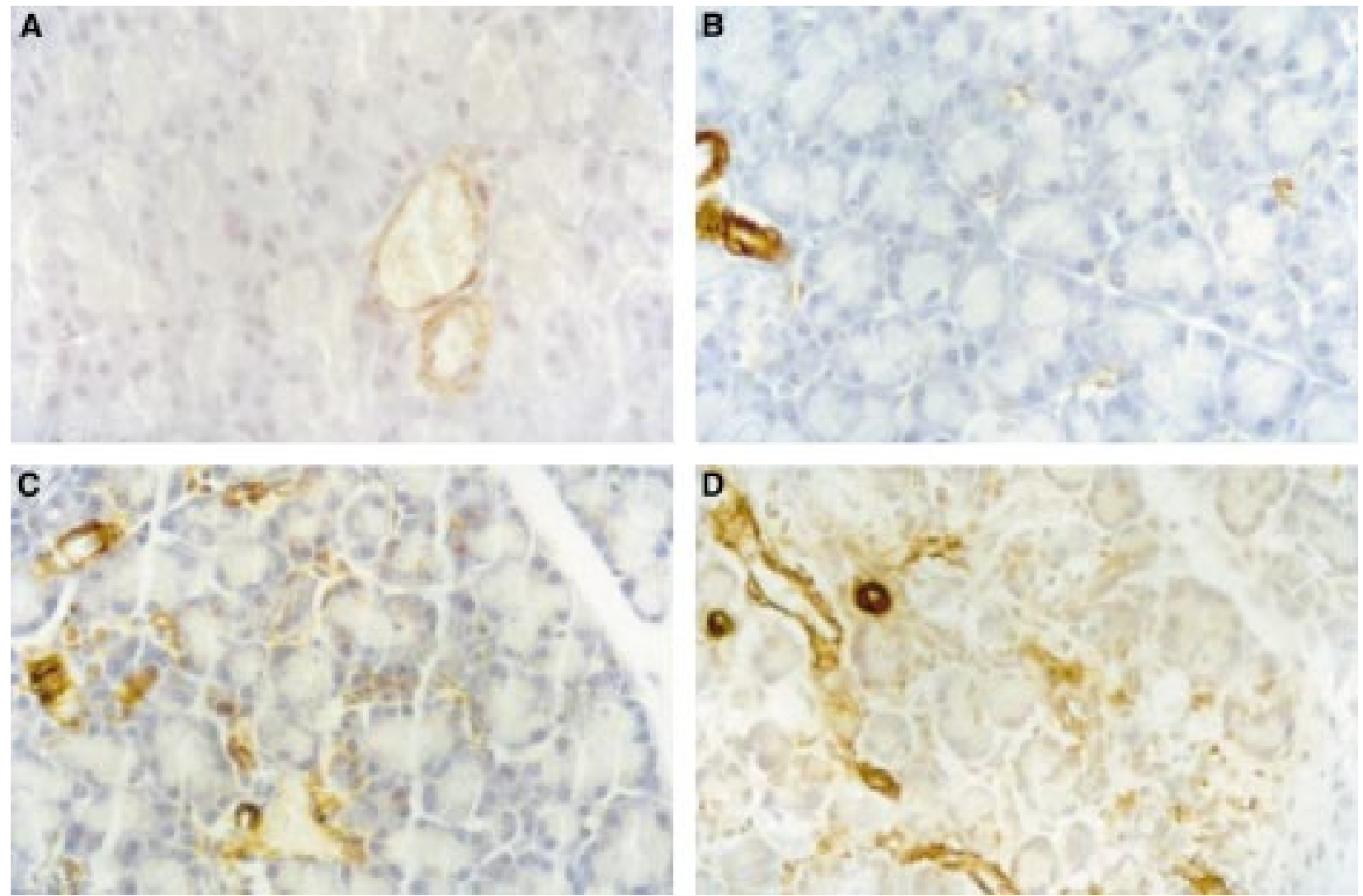

Figure 6 Representative examples of pancreatic specimens from controls $(A)$, caerulein alone $(B)$, cyclosporin alone $(C)$ or caerulein + cyclosporin $(D)$. groups as seen after immunostaining for smooth muscle a-actin (SMA). The antibody binds to cells in the vessel walls $(A)$. No immunoreactive interstitial cells were identified in controls, while some SMA positive cells were observed in the caerulein alone and cyclosporin alone groups, scattered throughout a well preserved pancreatic parenchyma. Vessel walls display strong staining. Abundant SMA interstitial cells were present in pancreatic specimens from caerulein + cyclosporin rats, often in the proximity of inflammatory infiltrates and increased deposition of connective tissue (original magnification $400 \times$ ). 


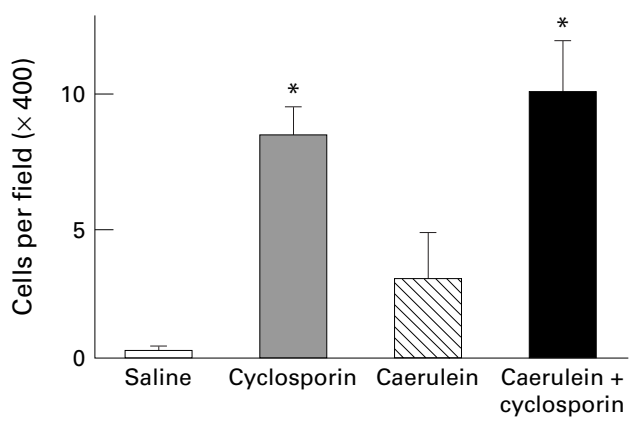

Figure 7 Effect of cyclosporin on myofibroblast density (interstitial cells immunoreactive for smooth muscle a-actin) in pancreatic sections. Myofibroblasts were present in the regenerative pancreas after caerulein pancreatitis induction. However, cyclosporin treatment increased considerably the number of myofibroblasts observed per field, even in the absence of an inflammatory reaction (cyclosporin alone group). ${ }^{\star} p<0.05 v$ caerulein alone.

generated by cyclosporin, administered by a weekly pulse regimen in association with repeated bouts of oedematous acute pancreatitis.

Once again, cyclosporin was the inducer of an inappropriate regenerative pancreatic response. Biochemical markers of gland atrophy such as pancreatic weight, total protein, and DNA content were all significantly reduced in the group of rats receiving the combination regimen, even after two weeks of the last bout of pancreatitis (fig 8). Furthermore, collagen deposition was greatly enhanced in this group as measured by tissue hydroxyproline concentration (fig 8) and examination of the histological appearance (fig 9). Indeed, two weeks after the last pancreatitis induction there was appre-
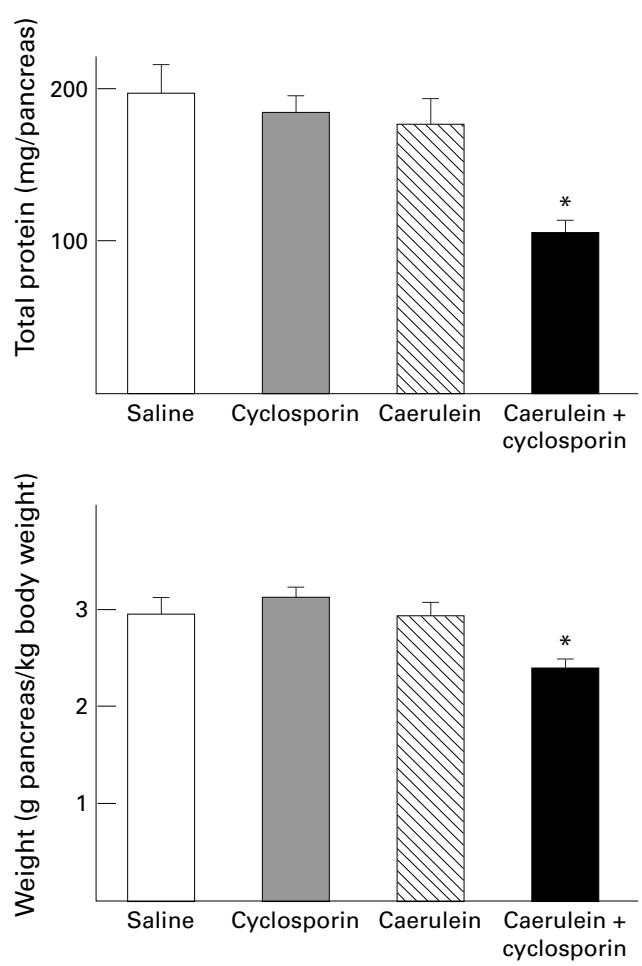

ciable atrophy of peripancreatic fat, areas of gland atrophy, and large bundles of fibrosis with diffuse lymphomonocytic infiltrates and proliferation of fibroblasts. Fine bands of fibrotic tissue extended inside the better preserved lobuli, indicating a generalised fibrotic process.

These findings contrasted with the absence of substantial morphological or biochemical abnormalities in groups of rats treated with either cyclosporin or caerulein alone.

\section{Discussion}

In this paper we describe the transformation of a highly efficient and well coordinated process of tissue repair-that is, regeneration after caerulein induced pancreatitis - into chroniclike pancreatitis featuring gland atrophy, persistent mononuclear infiltrates, and enhanced collagen deposition, all under the influence of a single pharmacological manipulation.

Cyclosporin interfered with pancreatic regeneration even when it was administered at weekly pulse doses (protocol B), noteworthy, without concurrence of any surgical interventions or anaesthetics. The latter may be a critical point as pentobarbital and other anaesthetics inactivate or inhibit the action of nitric oxide $^{29}$ and therefore may reduce splanchnic blood flow. ${ }^{30}$ Cyclosporin also reduces pancreatic blood flow, ${ }^{31}$ and consequently the combination of cyclosporin and anaesthetics may well potentiate damage to the gland.

Cyclosporin did not aggravate the severity of caerulein induced acute pancreatitis based on factors such as amylasaemia, tissue oedema,
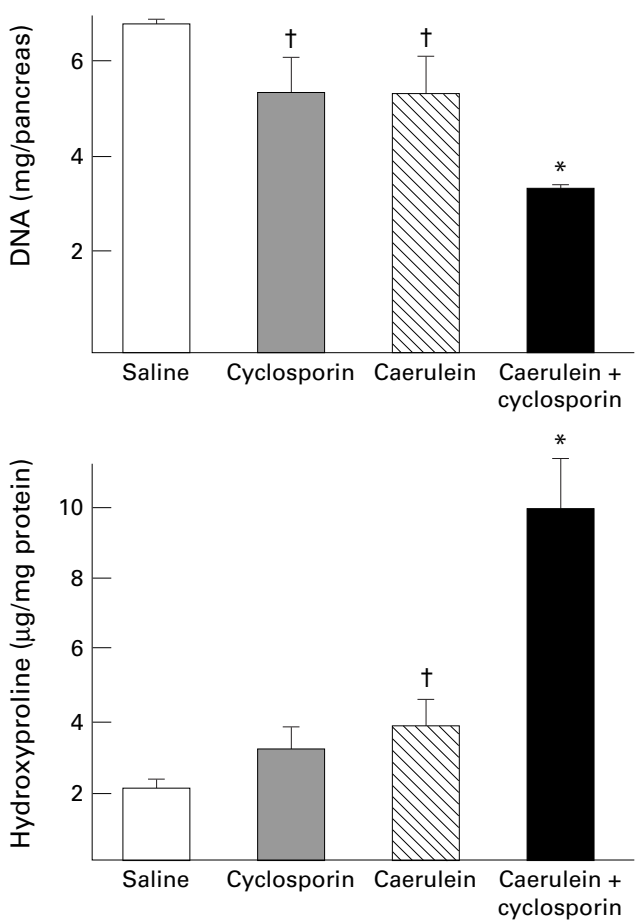

Figure 8 Effects of cyclosporin on a limited dose regimen (given before pancreatitis induction) on pancreatic recovery and collagen deposition two weeks after six weekly courses of caerulein induced pancreatitis (protocol B). Concurrent administration of cyclosporin significantly reduced pancreatic weight, total protein, and DNA content, indicating a higher degree of gland atrophy compared with rats receiving caerulein alone. In addition, hydroxyproline concentration was largely increased in the pancreas of rats receiving the combined treatment (cyclosporin + caerulein). ${ }^{\star} p<0.05 v$ all other groups. $t p<0.05$ v saline. 

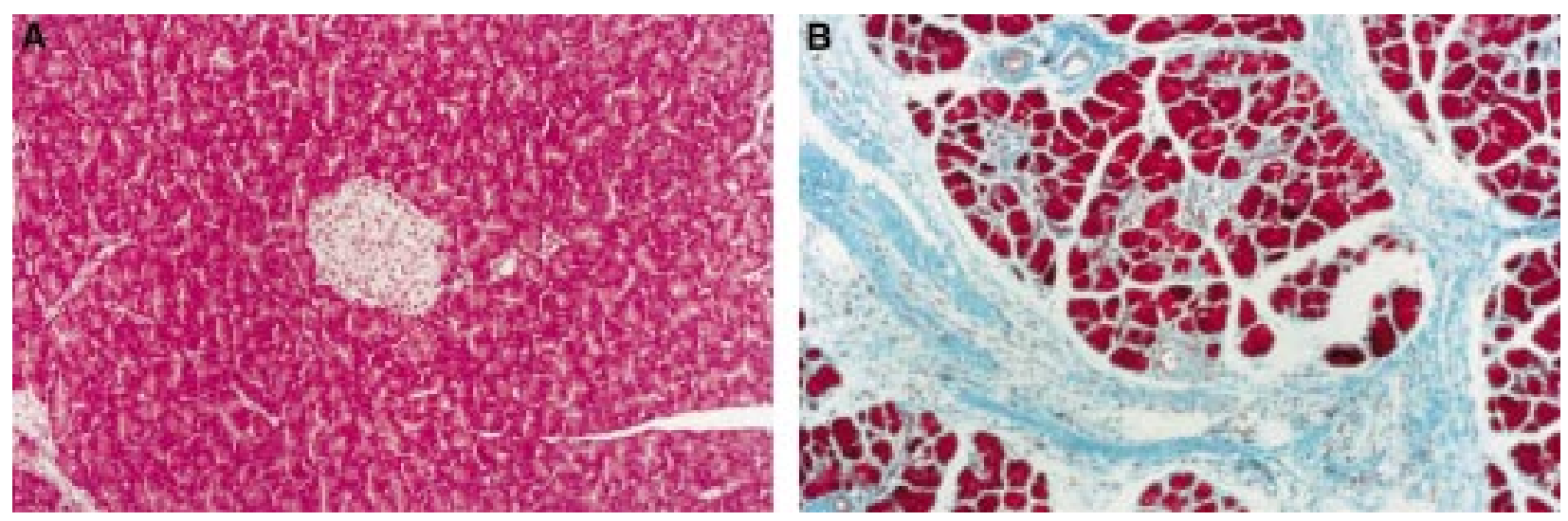

Figure 9 Histological findings two weeks after the last pancreatitis in pancreatic specimens from protocol B (induction of six courses of acute pancreatitis at weekly intervals). (A) Representative example of pancreatic tissue from caerulein alone group. Pancreatic architecture is normal. No inflammatory infiltrates or fibrosis are observed (haematoxylin and eosin stain; original magnification $\times 250$ ). (B) A remarkably different picture is observed in specimens from the caerulein + cyclosporin group. Prominent areas of perilobular and intralobular fibrosis are present. Lymphomonocytic infiltrates are abundant, especially in areas of increased connective tissue and acinar atrophy (Masson trichromic stain; original magnification $250 \times$ ).

and myeloperoxidase activity, or the morphological appearance. Our data suggest that repair mechanisms began to operate on equivalently damaged tissues in both the CR group and the CR+CsA group, independent of cyclosporin administration. Moreover, our results do not fully support previously formulated hypotheses that conditioned collagen accumulation in the pancreas to a necrosisfibrosis sequence, ${ }^{32}$ as both treatment regimens led to similar injury with a highly dissimilar outcome.

The pancreatic response to caerulein induced acute pancreatitis is characterised by inflammatory infiltrates, transient increase in TGF- $\beta$ expression, gland atrophy, collagen formation, fibroblast proliferation, and some acinar cell necrosis. ${ }^{1-6}$ Despite the extent of tissue damage, the pancreas regenerates completely leaving no signs of previous injury. Even repeated inductions of pancreatitis do not result in increased collagen deposition. ${ }^{7}$ Therefore caerulein induced acute pancreatitis is a good reference model of adequate tissue repair.

Our data strongly suggest that cyclosporin acts to distort the normal pancreatic repair mechanisms that would have otherwise fully restored pancreatic morphology. The process is shown to be associated with steadily increased plasma levels of TGF- $\beta$, myofibroblast proliferation, and a defective collagenase response to increased collagen formation.

Collagenase activity is expressed by extracellular matrix metalloproteinases that can be regulated by a number of cytokines such as interleukin $1 \beta$ or TGF- $\beta .^{33-35}$ The main sources of collagenases are fibroblasts and neutrophils. ${ }^{33}$ Both tissue collagenase activity and fibroblast dependent collagen synthesis can be modulated by TGF- $\beta .^{36}$

Indeed, the multifunctional TGF- $\beta$ s family of cytokines play a central role in the regulation of the coordinated events that characterise optimal wound healing. ${ }^{36-39}$ However, tissue fibrosis is prone to develop in response to sustained production of TGF- $\beta .^{37-39}$ This cytokine activates stellate cells and stimulates their differentiation into myofibroblasts in the liver, ${ }^{36}$ inhibits matrix degrading proteases (collagenase I, II, and III), ${ }^{35} 41$ and increases the production of collagenase inhibitors, facilitating fibrogenesis. ${ }^{38}$ TGF- $\beta$ is also known to inhibit the growth of epithelial cells and to stimulate fibroblast proliferation, and has been implicated in the pathogenesis of fibrosis in a number of other organs such as the kidney, lung, skin, and arteries. ${ }^{42}$

There are data suggesting that TGF- $\beta$ also modulates extracellular matrix formation in the pancreas. Thus, TGF- $\beta$ stimulates collagen synthesis from fibroblasts derived from human pancreas, ${ }^{43}$ and transgenic mice overexpressing TGF- $\beta$ show accumulation of extracellular matrix in the pancreas and fibroblast proliferation. ${ }^{44}$ Administration of a neutralising antibody against TGF- $\beta$ reduces fibronectin expression in rats with caerulein induced pancreatitis, ${ }^{43}$ whereas intravenous infusion of excess TGF- $\beta$ leads to increased collagen deposition and gland atrophy in mice. ${ }^{8}$ Moreover, TGF- $\beta$ expression seems to be enhanced in human pancreas with chronic pancreatitis. $^{45} 46$

We speculate that steady increased plasma levels of TGF- $\beta$, induced by cyclosporin, may account for a number of our experimental findings such as parenchymal atrophy, defective collagenase activity, and myofibroblast proliferation. After induction of caerulein pancreatitis, TGF- $\beta$ expression in the pancreas has been reported to be transiently elevated in the form of either a sharp peak of 2-3 days duration $^{34}$ or as a double wave peak occurring during the first week. ${ }^{5}$ Our data on plasma TGF- $\beta$ concentration after caerulein pancreatitis are in agreement with the above reports.

Cyclosporin is widely used in clinical practice, on account of its immunomodulatory properties. ${ }^{1147}$ In addition, cyclosporin increases plasma TGF- $\beta$ in humans and mice ${ }^{13}{ }^{14}$ and has been shown to promote fibrogenesis in kidney, heart, and gums. ${ }^{19} 20$ In vitro, cyclosporin induces collagen synthesis in fibroblasts. ${ }^{48}$

Cyclosporin toxicity to the pancreas is regarded to be of lesser relevance. Given for periods of weeks in large dose regimens, cyclosporin causes a reduction in stimulated pancreatic secretion and some acinar cell 
vacuolisation. However, no inflammatory reaction has been shown, ${ }^{16}$ and our results corroborate this point.

We have found, however, that cyclosporin induces the expression of pancreatic $\alpha$-SMA in interstitial fibroblast-like cells (myofibroblasts) and stimulates their proliferation even in the absence of an inflammatory reaction. In the liver, myofibroblasts (fibroblast-like cells expressing $\alpha$-SMA) represent the activated form of stellate cells, the main cell type involved in the synthesis of extracellular matrix components. ${ }^{49}$ In the pancreas, fibroblasts are involved in the reparative processes activated after caerulein induced acute pancreatitis and are known to proliferate after the initial injury. ${ }^{6}$ The normal pancreas contains interstitial cells that express desmin and vimentin, intermediate filaments that are also present in hepatic stellate cells. $^{50}$ In fibroblast-like cells from human pancreas in culture, TGF- $\beta$ enhances expression of $\alpha$-SMA and collagen synthesis. ${ }^{43}$ The basic nature of these observations has now been confirmed and expanded by other investigators who have renamed pancreatic myofibroblasts as activated stellate cells of the pancreas. ${ }^{51} 52$

However, despite increased plasma TGF- $\beta$ and myofibroblast transformation, we could not show any enhancement in pancreatic collagen deposition in response to cyclosporin alone. In our model, stimulation of extracellular matrix accumulation (fibrosis) required the participation of an additional aggressive factor, such as oedematous pancreatitis, a mild inflammatory disease. Under such combined conditions of injury and background cyclosporin, the normal pancreatic repair pattern characterised by a transient rise in plasma TGF- $\beta$, myofibroblast proliferation, collagen generation, and collagenase activity was substituted by a pathological post-injury pattern of steady high plasma levels of TGF- $\beta$, myofibroblast proliferation, increased collagen deposition, and inappropriate collagenase activation. The end result of this pathological process was that, instead of the customary restoration of normal pancreatic architecture expected after an acute caerulein challenge, there was a catastrophic disturbance of the regenerative sequence. The accentuated gland atrophy, persistent inflammatory reaction, and enhanced fibrosis formation brought about a morphological transformation that closely resembles human chronic pancreatic disease. ${ }^{53}$

This work was supported in part by grant FIS 98/0435.

1 Adler G, Hupp T, Kern HF. Course and spontaneous regression of acute pancreatitis in the rat. Virchows Arch 1979;382:31-47.

2 Elsässer HP, Adler G, Kern HF. Time course and cellular source of pancreatic regeneration following acute pancreatitis in the rat. Pancreas 1986;1:421-9.

3 Gress T, Müller-Pillosch F, Bachem M, et al. Enhancement of transforming growth factor $\beta 1$ expression in the rat pancreas during regeneration from caerulein-induced pancreatritis. Eur f Clin Invest 1994;24:679-85.

4 Menke A, Yamaguchi H, Gress TM, et al. Extracellular matrix is reduced by inhibition of transforming growth facmatrix is reduced by inhibition of transforming growth factor 131 in

5 Riesle E, Friess H, Zhao L, et al. Increased expression of transforming growth factor $3 s$ after acute oedematous pan- creatitis in rats suggests a role in pancreatic repair. Gut 1997;40:73-9.

6 Elsässer HP, Adler G, Kern HF. Fibroblast structure and function during regeneration from hormone-induced acute pancreatitis in the rat. Pancreas 1989;4:169-78.

7 Elsässer HP, Haake T, Grimming M, et al. Repetitive cerulein-induced pancreatitis and pancreatic fibrosis in the rat. Pancreas 1992;7:385-90.

8 Van Laethem J-L, Robberecht $\mathrm{P}$, Résibois $\mathrm{A}$, et al. Transforming growth factor $\beta$ promotes development of fibrosis after repeated courses of acute pancreatitis in mice. Gastroenterology 1996;110:576-82.

9 Takano S, Kimura T, Yamaguchi H, et al. Effects of stress on the development of chronic pancreatitis. Pancreas 1992;7: $548-55$

10 Suthanthiran M, Morris RE, Strom TB. Immunosupressants: cellular and molecular mechanisms of action. Am f Kidney Dis 1996;28:159-72.

1 Faulds D, Goa K, Benfield P. Cyclosporin. A review of its pharmacodynamic and pharmacokinetic properties, and therapeutic use in immunoregulatory disorders. Drugs 1993:45:953-1040.

$12 \mathrm{Li} \mathrm{B}$, Sehajpal P, Khanna A, et al. Differential regulation of transforming growth factor beta and interleukin 2 genes in human T cells. F Exp Med 1991;174:1259-62.

13 Kanna A, Kapur S, Sharma VK, et al. In vivo overexpression of transforming growth factor- $\beta 1$ in mice: stimulation by cyclosporin. Transplantation 1997;63:1037-9.

14 Shin GT, Kanna A, Sharma VK, et al. In vivo overexpression of transforming growth factor- $\beta 1$ in humans: stimulation by cyclosporin. Transplant Proc 1997;29:284

15 Kahan BD, Ried M, Newburger J. Cyclosporin A tissue levels in cadaveric renal allograft recipients. Transplantation 1983;35:96-9.

16 Meyer-Alber A, Hocker M, Fetz I, et al. Differential inhibitory effects of serine/threonine phosphatase inhibitors and calmodulin antagonist on phosphoinositol/calcium- and cyclic adenosine monophosphate-mediated pancreatic amylase secretion. Scand f Gastroenterol 1995;30:384-91.

17 Hirakawa K, Yoshimura N, Tsuchihasi Y, et al. Cyclosporininduced morphological changes in rat exocrine pancreas. induced morphological changes

18 Shihab FS. Cyclosporin nephropathy: pathophysiology and clinical impact. Semin Nephrol 1996;16:536-47.

9 Kolar F, Papousek F, MacNaughton C, et al. Myocardial fibrosis and right ventricular function of heterotopically ransplanted hearts in rats treated with cyclosporin. $\mathrm{Mol}$ Cell Biochem 1996;163-164:253-60.

20 Wysocki GP, Gretzinger HA, Laupacis A, et al. Fibrous hyperplasia of the gingiva: a side effect of cyclosporin A therapy. Oral Surg Oral Med Oral Pathol 1983;55:274-8.

21 Rojkind M, Gonzalez E. An improved method for determining specific radioactivities of ${ }^{14} \mathrm{C}$-proline and ${ }^{14} \mathrm{C}$ hydroxyproline in collagen and non collagen proteins. Anal Biochem 1974;57:1-7.

22 Mourelle M, Guarner F, Malagelada JR. Polyunsaturated phosphatidylcholine prevents stricture formation in a rat model of colitis. Gastroenterology 1996;110:1093-7.

23 Chavira R, Burnett TJ, Hageman JH. Assaying proteinases with azocoll. Anal Biochem 1984;136:446-50.

24 López JM, Valderrama R, Navarro S, et al. Aprotinin inhibits unspecific degradation of collagen in rat and human pancreas. Int $\mathcal{F}$ Pancreatol 1996;19:55-60.

25 Labarca C, Paigen K. A simple, rapid, and sensitive DNA assay procedure. Anal Biochem 1980;102:344-52.

26 Grisham MB, Benoit JN, Granger DN. Assessment of leukocyte involvement during ischemia and reperfusion of the intestine. Methods Enzymol 1990;186:729-41.

27 Yamada T, Sartor RB, Marshall S, et al. Mucosal injury and inflammation in a model of chronic granulomatous colitis in rats. Gastroenterology 1993;104:759-71.

28 Ito $\mathrm{T}$, Kimura $\mathrm{T}$, Yamaguchi $\mathrm{H}$ et al. Acute pancreatitis induced by Cyclosporin A under stimulation of the pancreas by caerulein. Pancreas 1993;8:693-9.

29 Terasako K, Nakamura K, Toda H, et al. Barbiturates inhibit endothelium-dependent and independent relaxations mediated by cyclic GMP. Anesth Analg 1994;78:823-30.

30 Colombato LA, Sabba C, Polio J, et al. Influence of anesthesia, postanesthetic state and restrain on superior mesenteric
arterial flow in normal rats. Am f Physiol 1991;260:G1-6.

31 Ito T, Furukawa M, Liu X, et al. Immunosuppressive agents induce the reduction of local pancreatic blood flow. Pancreas 1995;11:102-3.

32 Klöppel G, Maillet B. The morphological basis for the evolution of acute pancreatitis into chronic pancreatitis. Virchows Arch 1992;420:1-4.

33 Dioszegi M, Cannon P, Van Mart HE. Vertebrate collagenases. Methods Enzymol 1995;248:413-31.

34 Wahl SM, Allen JB, Weeks BS, et al. Transforming growth factor $\beta$ enhances integrin expression and type IV collagenase secretion in human monocytes. Proc Natl Acad Sci USA 1993;90:4577-81

35 Overall CM, Wrana JL, Sodek J. Independent regulation of collagenase, $72-\mathrm{kDa}$ progelatinase, and metalloendoproteinase inhibitor expression in human fibroblasts by transforming growth factor-beta. F Biol Chem 1989;264:1860-9.

36 Gressner AM, Bachem MG. Molecular mechanisms of liver fibrogenesis: a homage to the role of activated fat-storing cells. Digestion 1995;56:335-46.

37 Wahl SM. Transforming growth factor $\beta$ : the good, the bad and the ugly. F Exp Med 1994;180:1587-90.

38 Border WA, Noble NA. Transforming growth factor $\beta$ in tissue fibrosis. N Eng f Med 1994;331:1286-92. 
39 Border WA, Ruoslahti E. Transforming growth factor- $\beta$ in disease: the dark side of tissue repair. F Clin Invest 1992;90. disease: $1-7$.

40 Bachem MG, Sell KM, Melchior R, et al. Tumor necrosis factor alpha $(\mathrm{TNF} \alpha)$ and transforming growth factor $\beta 1$ (TGF- $\beta 1$ ) stimulate fibronectin synthesis and the transdifferentiation of fat-storing cells in the rat liver into myofibroblasts. Virchows Arch 1993;63:123-30.

41 Edwards DR, Murphy G, Reynolds JJ, et al. Transforming growth factor beta modulates the expression of colag and metalloproteinase inhibitor. EMBO f 1987;6:1899-904

42 Yamamoto T, Noble NA, Miller DE, et al. Sustained expression of TGF-beta 1 underlies development of progressive kidney fibrosis. Kidney Int 1994;45:916-27.

43 Saotome $\mathrm{T}$, Inove $\mathrm{H}$, Fujiyama $\mathrm{M}$, et al. Morphological and immunocytochemical identification of periacinar fibroblast-like cells derived from human pancreatic acini. Pancreas 1997;14:373-82.

44 Lee MS, Gu D, Feng L, et al. Accumulation of extracellular matrix and developmental dysregulation in the pancreas by matrix and developmental dysregulation in the pancreas by transgenic production of transform

45 Van Laethem J-L, Devière J, Résibois A, et al. Localization of transforming growth factor $\beta 1$ and its latent binding protein in human chronic pancreatitis. Gastroenterology 1995;108:1873-81.
46 Slater SD, Williamson RCN, Foster CS. Expression of transforming growth factor- $\beta 1$ in chronic pancreatitis. Digestion 1995;56:237-41.

47 Starzl TE. Clinical aspects of cyclosporine therapy: a summation. Transplant Proc 1983;15(suppl 1):3103-7.

48 Wolf G, Killen PD, Neilson EG. Cyclosporin A stimulates transcription and procollagen secretion in tubulointerstitial fibroblasts and proximal tubular cells. F Am Soc Nephrol 1990;1:918-22.

49 Friedman SL, Roll FJ, Boyles J, et al. Hepatic lipocytes: the principal collagen producing cells of the liver. Proc Natl Acad Sci USA 1985;82:8681-5.

50 Fujimoto T, Singer SJ. Immunocytochemical studies of desmin and vimentin in pericapillary cells of chicken. $\mathcal{f}$ Histochem Cytochem 1987;35:1105-15.

51 Apte M V, Haber PS, Moran CS, et al. Pancreatic stellate cells produce collagen and other extracellular matrix proteins and exhibit a proliferative response to plateletderived growth factor (PDGF) [abstract]. Gastroenterology 1998;114:A438.

52 Bachem MG, Schneider E, Gross H, et al. Identification, culture and characterization of pancreatic stellate cells in rats and humans. Gastroenterology 1998;115:421-32.

53 Klöppel G, Maillet B. Pathology of acute and chronic pancreatitis. Pancreas 1993;8:659-70. 